\title{
Mathematical modelling of digesta passage rate, mean retention time and in vivo apparent digestibility of two different lengths of hay and big-bale grass silage in ponies
}

\author{
M. J. S. Moore-Colyer ${ }^{1 *}$, H. J. Morrow ${ }^{2}$ and A. C. Longland ${ }^{3}$ \\ ${ }^{1}$ Institute of Rural Studies, University of Wales Aberystwyth, Llanbadarn Campus, Aberystwyth SY23 3AL, \\ Wales, UK \\ ${ }^{2}$ Enniskillen College of Agriculture, Levaghy, Enniskillen, Co Fermanagh BT74 4GF, UK \\ ${ }^{3}$ Institute of Grassland and Environmental Research, Plas Gogerddan, Aberystwyth SY23 3EB, Ceredigion, \\ Wales, UK
}

(Received 15 July 2002 - Revised 23 January 2003 - Accepted 21 February 2003)

\begin{abstract}
Welsh-cross pony geldings (about $300 \mathrm{~kg}$ live weight) were used in a $4 \times 4$ Latin square experiment to determine the rate of passage and apparent digestibility of unchopped big-bale grass silage (BBL), chopped big-bale grass silage (BBS), unchopped grass hay (HL) and chopped grass hay (HS) offered at approximately $15 \mathrm{~g} / \mathrm{kg}$ live weight per d. On day 1 of collection weeks, ponies were fed $85 \mathrm{~g}$ ytterbium chloride hexahydrate-marked feed $1.5 \mathrm{~h}$ after the morning meal. Total faecal collections commenced $8 \mathrm{~h}$ later and continued for $168 \mathrm{~h}$. Apparent digestibilities of feed DM, organic matter (OM), crude protein (CP, N $\times 6 \cdot 25)$, acid-detergent fibre (ADF) and neutral-detergent fibre (NDF) were also determined. Faecal excretion data were subjected to the models of Pond et al. (1988) and digesta mean retention time (MRT) calculated from these models and using the algebraic method of Thielmans et al. (1978). Silage had significantly $(P<0 \cdot 05)$ higher digestibilities of DM, OM, CP, ADF and NDF than hay; however, chop length had no effect. All the models of Pond et al. (1988) accurately described $\left(R^{2}>0.8\right)$ the pattern of faecal marker excretion. MRT of BBL $(29.0 \mathrm{~h})>\mathrm{BBS}(27 \mathrm{~h})>\mathrm{HS}$ and HL (26h). Compartmental analysis using the G3 model of Pond et al. (1988) showed BBL and HS diets had longer MRT in the time-dependent compartment, whereas BBS and HL had longer MRT in the time-independent compartment. Results from this experiment indicate that BBL and BBS are readily accepted and digested by ponies. While $\mathrm{Yb}$ is a successful external marker for determining total tract MRT and for modelling faecal excretion curves in horses, the results did not allow any definite conclusions to be drawn on digesta MRT within the different compartments of the equid gut.
\end{abstract}

Digesta passage rate: Mean retention time: Apparent digestibility: Horse

Mathematical modelling of faecal excretion data using indigestible external markers is a non-invasive method that can be used to obtain digesta passage rate and mean retention time (MRT) in animals. Such models simulate aspects of the digestive system and so allow a greater understanding of digesta kinetics. Although mathematical models have been applied to ruminant animal data (Uden et al. 1982; Mertens, 1989; Lalles et al. 1991; Ellis et al. 1994), the process of using these models to compartmentalise the digestive tract is far from established and rarely have these models been used to describe the passage of digesta through the equid gastrointestinal tract.

Mathematical models are generally categorised into two types: the first are time-independent models (Grovum \& Williams, 1973; Dhanoa et al. 1985), which are deterministic in nature and therefore assume that digesta flows irreversibly through a fixed number of sequential compartments, according to first order kinetics (Lalles et al. 1991). The second are termed time-dependent models. These are based on assumptions of probability (stochastic models) and use $\gamma$-functions (non-exponential residence time distributions) to describe the time-dependent passage of digesta through different segments of the gastrointestinal tract. The inherent flexibility of timedependent models has allowed them to be successfully fitted to ruminant animal faecal excretion data (Pond et al. 1988) where the more rigid time-independent models have failed (Milne et al. 1978; Ellis et al. 1979; Uden et al. 1982). The failure of time-independent models may be partly attributed to the fact that they assume constant volume and instantaneous mixing of digesta within a gut compartment, along with equal opportunity for particle escape irrespective of digesta residence time (Ellis et al. 1994). Digesta passing through the

\footnotetext{
Abbreviations: ADF, acid-detergent fibre; BBL, unchopped big-bale grass silage; BBS, chopped big-bale grass silage; $\mathrm{CP}$, crude protein (N $\times 6 \cdot 25)$; HL, unchopped hay; HS, chopped hay; MRT, mean retention time; NDF, neutral-detergent fibre; OM, organic matter; TD, time delay.

* Corresponding author: Dr Meriel J. S. Moore-Colyer, fax +44 1970 611564, email mem@aber.ac.uk
} 
fermentation section of the equid gut, which consists of the caecum and the four distinct regions of the large colon (Jackson, 1998), has to pass through narrow flexures as it flows through right and left ventral, to left and right dorsal chambers. While mixing within each of these chambers may occur quickly, it is unlikely that the passage of digesta through the entire large intestine would follow first order kinetics. Therefore, the physiological arrangement of the equid digestive tract will cause digesta passage to be a time-dependent process, whereby the probability of particle escape is increased with time. This assumption is supported by a previous preliminary study in ponies of Moore-Colyer (2000), which found time-dependent models to be more successful at describing the pattern of faecal excretion than time-independent models.

Published accounts on the process of mathematically modelling faecal excretion data in horses are strictly limited (Corino et al. 1992), with most workers confining their calculations to a determination of digesta MRT using a variety of algebraic equations (Uden et al. 1982; Pearson \& Merritt, 1991; Nyberg et al. 1993). Such information has indicated that the lower degradability of certain forage foodstuffs in equids compared with ruminant animals (Vander Noot \& Gilbreath, 1970) is due, at least in part, to the shorter MRT within the equid gastrointestinal tract (Uden et al. 1982). However, to date no attempt has been made at using time-dependent models to track the passage of digesta through the individual gut compartments, and therefore to try to explain why the degradability of certain foodstuffs is more influenced by MRT than others.

Information on the behaviour of digesta within the different segments of the gut would allow a clearer understanding of the dynamic interactions between feed, enzymes and gut microflora and would promote better ration formulation for horses engaged in a wide variety of activities.

The objectives of the following experiment were to assess the suitability of $\mathrm{Yb}$ as an indigestible marker for measuring digesta passage rate in ponies and to examine the accuracy with which three time-dependent and two time-independent (Dhanoa et al. 1985; Pond et al. 1988) models described the pattern of faecal excretion in ponies. On the basis of these models, biological interpretation was attempted, whereby the individual compartments identified by the model were designated as representing certain regions within the equid gastrointestinal tract. In addition, the digestibility of two different chop-lengths of hay and silage were measured, to determine if particle length had any influence on the degradability and MRT of the feeds within the gastrointestinal tract of ponies.

\section{Materials and methods}

\section{Animal management}

Four mature Welsh-cross pony geldings (about $300 \mathrm{~kg}$ live weight) were used in a $4 \times 4$ Latin square change-over design experiment consisting of four $21 \mathrm{~d}$ periods, each split into a $14 \mathrm{~d}$ adaptation phase and a $7 \mathrm{~d}$ faecal collection period. Ponies received a similar amount of feed for adaptation and collection periods and were individually loose-housed in $3.6 \times 3.6 \mathrm{~m}$ loose boxes; the floors were covered with rubber matting (Davies and Co, Kettering, Northants, UK) and water was available ad libitum. During adaptation weeks the ponies were allowed $30 \mathrm{~min}$ free exercise in an outdoor sand arena, while in collection weeks, ponies were walked in hand, covering a distance of $2.25 \mathrm{~km}(1.4 \mathrm{miles}) / \mathrm{d}$.

The ponies were offered one of four diets at a level equivalent to $15 \mathrm{~g}$ feedstuff $\mathrm{DM} / \mathrm{kg}$ live weight per $\mathrm{d}$. The diets comprised unchopped big-bale grass silage (BBL), chopped big-bale grass silage (BBS), unchopped grass hay (HL) and chopped grass hay (HS). Precise details on the cutting date of the timothy (Phleum pratense)perennial rye grass (Lolium perenne) hay were not available, but the number of flowering heads in the bales was indicative of a crop cut in mid-late summer. The big-bale silage was conserved on the University of Wales Lluest farm from a perennial rye grass sward, which received $0.5 \mathrm{~kg} \mathrm{~N} / \mathrm{km}^{2}$ on $1 \mathrm{st}$ March and $1.5 \mathrm{~kg} / \mathrm{km}^{2}$ as $20: 10: 10$ $\mathrm{N}: \mathrm{P}: \mathrm{K}$ on 9 th April. The grass was mowed on 8 th June and left to wilt for $48 \mathrm{~h}$ before being made into big round bales and wrapped in four layers of heavy-gauge plastic wrap. The diets were fed in two equal meals per $\mathrm{d}$ at 08.00 and 20.00 hours. Equivite mineral and vitamin supplement (60g; Equivite; Spillers Speciality Feeds, Milton Keynes, UK) was mixed with $20 \mathrm{~g}$ soaked sugarbeet pulp and offered after the morning feed had been eaten. In addition, each pony had free access to a salt lick, located in the corner of each stable. Pony live weight was recorded at 10.30 hours every Monday throughout the trial period using a weighbridge (Basic Weigher; Tyler Farm Equipment, Grantham, Lincs, UK).

\section{Food preparation}

The chopped hay and silage rations were prepared from the same bales that were used for the corresponding long forage samples. Each morning, the daily silage ration was removed from the bale with a fork and placed into 40 litre plastic tubs. The proportion to be chopped was then fed into a straw chopper, which consisted of a set of rotating knives fitted to a Honda G3000, $5 \cdot 22 \mathrm{~kW}$ petrol engine and a WIC 8705 drum (Fosse, York, UK). The chopped forage was then stored in covered 40 litre plastic tubs until it was fed to the ponies. The hay was chopped in the same manner as the silage except that sufficient hay to last for 3 weeks was chopped at one time.

\section{Particle size determination}

A sample of fresh forage $(25 \mathrm{~g})$ was taken from each batch of food to determine the particle size. The length of each individual particle was measured and put into one of the following size categories (mm): 0-25, 26-50, 51-75, $76-100,101-150,>150$. Each group of particles were then placed into foil trays and weighed to determine the percentage of particles within each length category.

\section{Preparation of ytterbium-marked food}

Yb-marked food was prepared using ytterbium (III) chloride hexahydrate (99\%; Aldrich Chemical Company, 
Gillingham, Dorset, UK), by the immersion method of Teeter et al. (1984). At 09.30 hours on the Monday of each collection week $85 \mathrm{~g}$ Yb-marked food mixed in with $100 \mathrm{~g}$ pre-soaked sugarbeet pulp was fed to the ponies.

\section{Apparent digestibility and nutritive value measurements}

During the $7 \mathrm{~d}$ faecal collection periods in vivo apparent digestibilities of $\mathrm{DM}$ organic matter $(\mathrm{OM})$, crude protein $(\mathrm{CP}, \mathrm{N} \times 6 \cdot 25)$, acid-detergent fibre (ADF) and neutraldetergent fibre (NDF) were determined by total faecal collections. Daily faecal samples for each pony were separately stored in covered plastic bins for $24 \mathrm{~h}$, whereupon faeces were thoroughly mixed and a sub-sample of $800 \mathrm{~g}$ was taken and stored at $-20^{\circ} \mathrm{C}$ prior to lyophilisation. At the end of each collection period, a bulk faecal sample was compiled from the $7 \mathrm{~d}$ outputs, according to the proportion of the daily faecal DM output for each pony (Cochran \& Gaylean, 1994).

Composite samples of the diets and the dried, bulked faecal samples, milled to pass a $1 \mathrm{~mm}$ screen, were subsequently analysed for DM, OM, CP, ADF and NDF contents according to the methods of the Association of Official Analytical Chemists (1990).

\section{Digesta rate of passage measurements}

Faecal collections commenced $8 \mathrm{~h}$ after the administration of the $\mathrm{Yb}$; this involved collecting all defecations up to $48 \mathrm{~h}$, followed by $2 \mathrm{~h}$ collections up to $72 \mathrm{~h}, 4 \mathrm{~h}$ collections up to $96 \mathrm{~h}, 8 \mathrm{~h}$ collections from $96-120 \mathrm{~h}$ and $12 \mathrm{~h}$ collections up to $168 \mathrm{~h}$. Time of faecal voiding and subsequent faecal sample weight were recorded for every sample. A $200 \mathrm{~g}$ sub-sample from each collection was then placed into a pre-weighed foil tray, weighed and dried in a force-draught oven at $60^{\circ} \mathrm{C}$ for $48 \mathrm{~h}$ and stored at room temperature, prior to chemical analysis.

\section{Preparation of feed and faecal samples for ytterbium analysis}

The concentrations of $\mathrm{Yb}$ in feed and faecal samples were determined as follows: $2 \mathrm{~g}$ dried, ground sample $(1 \mathrm{~mm}$ mesh screen) were weighed into a numbered crucible and placed into a furnace and ashed at $550^{\circ} \mathrm{C}$ for $2 \mathrm{~h}$. After cooling, several drops of $\mathrm{HNO}_{3}(50 \mathrm{ml} / \mathrm{l})$ were added to the crucible to dissolve the ash; this was then transferred to a $20 \mathrm{ml}$ volumetric flask and made up to volume using additional $\mathrm{HNO}_{3}(50 \mathrm{ml} / \mathrm{l})$ solution. After thorough mixing, the solution was transferred to a plastic bottle and left for $12 \mathrm{~h}$ to settle, whereupon the supernatant fraction was decanted into a clean numbered medical bottle. A sample of this solution $(0.1 \mathrm{ml})$ plus $9.6 \mathrm{ml}$ milli-Q water (Fisher Scientific Ltd, Loughborough, Leics., UK), $0.2 \mathrm{ml}$ concentrated $\mathrm{HNO}_{3}$, and $0.1 \mathrm{ml} \mathrm{Rh}(10 \mu \mathrm{g} / \mathrm{ml}$ $\left.\mathrm{HNO}_{3}(50 \mathrm{ml} / \mathrm{l})\right)$ solution were placed into sample tubes, thoroughly shaken and fed through an induction-coupled plasma MS. The pick-up time for the samples was set at $35 \mathrm{~s}$ with a scan time of $35 \mathrm{~s}$. Between samples the probe was placed in $\mathrm{HNO}_{3} \quad(50 \mathrm{ml} / \mathrm{l})$ to minimise cross-contamination of samples.

\section{Data analysis}

Faecal excretion data were fitted to the four models of Pond et al. (1988) and the multi-compartmental model of Dhanoa et al. (1985). The equations used to fit the G1, G2, G3 and G4 models are detailed and these were solved using a SAS computer program (1985; SAS Inst. Inc, Cary, NC, USA) with the procedure recommended by Moore et al. (1992).

$$
\begin{array}{ll}
\mathrm{F}= & \mathrm{C}_{2} \mathrm{k}_{1}\left(\mathrm{e}^{-\mathrm{k}_{2} \mathrm{TD}}-\mathrm{e}^{-\mathrm{k}_{1} \mathrm{TD}}\right) /\left(\mathrm{k}_{1}-\mathrm{k}_{2}\right), \\
\mathrm{F}= & \mathrm{C}_{2}\left(\delta^{2} \mathrm{e}^{-\mathrm{k}_{2} \mathrm{TD}}-\mathrm{e}^{-\lambda_{1} \mathrm{TD}}\left(\delta^{2}+\delta \lambda_{1} \mathrm{TD}\right)\right), \quad(\mathrm{G} 2 \text { model }) \\
\mathrm{F}= & \mathrm{C}_{2}\left(\delta^{3} \mathrm{e}^{-\mathrm{k}_{2} \mathrm{TD}}-\mathrm{e}^{-\lambda_{1} \mathrm{TD}}\left(\delta^{3}+\delta^{2} \lambda_{1} \mathrm{TD}\right.\right. \\
\quad & \left.\left.\quad+\delta^{2} \lambda_{1} \mathrm{TD}^{2} / 2\right)\right) \\
\text { and } \quad & \quad(\mathrm{G} 3 \text { model }) \\
\mathrm{F}= & \mathrm{C}_{2}\left(\delta^{4} \mathrm{e}^{-\mathrm{k}_{2} \mathrm{TD}}-\mathrm{e}^{-\lambda_{1} \mathrm{TD}}\left(\delta^{4}+\delta^{3}+\delta^{2} \lambda_{1} \mathrm{TD}\right.\right. \\
& \left.\left.+\delta^{3} \lambda_{1} \mathrm{TD}^{3} / 3\right)\right),
\end{array}
$$

where $\mathrm{F}$ is the fractional concentration of marker, $\mathrm{C}_{2}$ is the initial concentration in second compartment, $\mathrm{C}_{2}$ is dose (D)/volume at second compartment $(\mathrm{V}), \mathrm{k}_{1}$ and $\mathrm{k}_{2}$ are exponentially distributed rate parameters, $\lambda$ is the rate parameter for $\gamma$-distributed residence times, $\delta=\lambda_{1} /$ $\left(\lambda_{1}-\mathrm{k}_{2}\right)$ and $\mathrm{TD}=(\mathrm{t}-\lambda)$ time delay (time post - dose to first appearance of marker in the faeces) (Pond et al. 1988).

All models were tested for accuracy of fit using linear regression, to determine $R^{2}$ values for each pony on each diet. The $R^{2}$ values were then subjected to a two-way ANOVA using Genstat 5 (1993; Lawes Agricultural Trust, Rothamsted Experimental Station, Harpendon, Herts., UK) and least significant difference test to determine if significant differences existed between the 'goodness of fit' of the models when fitting different diets, and if a difference existed between models within a diet.

The results obtained from the four compartmental models of Pond et al. (1988) were then used to calculate total tract MRT.

The MRT for the G1, G2, G3 and G4 models of Pond et al. (1988) were obtained from:

$$
\begin{array}{ll}
1 / \lambda+1 / \mathrm{k}_{2}+\mathrm{TD}=\mathrm{TMRT}, & (\mathrm{G} 1 \text { model }) \\
2 / \lambda+1 / \mathrm{k}_{2}+\mathrm{TD}=\mathrm{TMRT}, & (\mathrm{G} 2 \text { model }) \\
3 / \lambda+1 / \mathrm{k}_{2}+\mathrm{TD}=\mathrm{TMRT}, & (\mathrm{G} 3 \text { model })
\end{array}
$$

and

$$
4 / \lambda+1 / \mathrm{k}_{2}+\mathrm{TD}=\mathrm{TMRT}, \quad(\mathrm{G} 4 \text { model })
$$

where TMRT is the total tract MRT. The algebraic equation of Thielmans et al. (1978) was used to determine MRT from the following equation:

$$
\mathrm{MRT}=\Sigma \mathrm{ti} \mathrm{Ci} \Delta \text { tiright } / \Sigma \mathrm{Ci} \Delta \mathrm{ti},
$$

where ti is the time post dose, taken as the mid-point between successive samples, $\mathrm{Ci}$ is the concentration of marker in faeces and $\Delta \mathrm{ti}$ is the difference in time between successive samples. 
The MRT from the one algebraic and four compartmental models were then subjected to a two-way ANOVA (Genstat 5, 1993; Lawes Agricultural Trust) and a least significant difference test, to determine if significant differences existed in MRT between BBL, BBS, HL and HS and if differences existed between the MRT obtained from different models within diets.

\section{Compartmental analysis}

The four models were tested for goodness of fit to observed data using $R^{2}$ analysis. The model of best fit, determined from the $R^{2}$ data, was then used for further compartmental analysis. The mean digesta passage rates and retention times for each diet through each of the gastrointestinal tract compartments of the four ponies were then calculated and these values subjected to an analysis of variance (Genstat 5, 1993; Lawes Agricultural Trust). Thus, mean values were obtained for a time-dependent compartment $\lambda$, a time-independent compartment $\mathrm{k}_{2}$ and a TD factor $\tau$ for each diet.

\section{Results}

\section{Animal management}

All four ponies remained healthy during the 12-week experimental period and readily consumed the forage offered to them each day. Feed refusals were negligible, ranging from $44 \mathrm{~g} \mathrm{DM}$ for $\mathrm{HS}$ to $123 \mathrm{~g} \mathrm{DM}$ for BBS/d. All the ponies readily accepted the oral pulse dose of $85 \mathrm{~g} \mathrm{Yb}$-marked food at the start of each collection period.

\section{Food composition}

The chemical compositions of each of the four experimental forages are detailed in Table 1. The DM content of BBL was slightly lower than for BBS (353 v. $371 \mathrm{~g} / \mathrm{kg}$ respectively): this difference is likely to be due to the additional handling and the chopping of the BBS forage. All other variables were similar between the chopped and long silage. Similarly, no differences in chemical compositions were noted between HS and HL. The two silages contained more that fourfold as much moisture as the hay, 190 and $195 \mathrm{~g}$ less $\mathrm{ADF}$ and NDF respectively and $60 \mathrm{~g}$ more $\mathrm{CP}$ $(\mathrm{N} \times 6.25)$ than the hay/kg DM. The average particle size was greatest for the BBL at $293 \mathrm{~mm}$, followed by the HL at $180 \mathrm{~mm}$, with the chopped BBS and HS being only 68 and $53 \mathrm{~mm}$ respectively.

\section{Food intake and apparent digestibility measurements}

Table 2 details the average DM intake of the ponies when offered the four forages at the rate of $15 \mathrm{~g} / \mathrm{kg}$ live weight per $\mathrm{d}$. The DM of the silage varied slightly from bale to bale throughout the 12-week experiment. Consequently, the amount of DM offered per d varied, resulting in significantly $(P<0.05)$ higher intakes of BBS $(0.58 \mathrm{~kg} / \mathrm{d})$ compared with intakes of the two hay diets. No difference in intake was noted between the BBL and any of the other diets. Furthermore, no significant differences in the
Table 1. Composition and particle size of the four experimental feeds offered to the four ponies $(\mathrm{g} / \mathrm{kg} \mathrm{DM})^{\star}$

(Mean values)

\begin{tabular}{lrrrr}
\hline & \multicolumn{4}{c}{ Diet† } \\
\cline { 2 - 5 } & BBL & BBS & HL & HS \\
\hline DM & 353 & 371 & 861 & 860 \\
ADF & 307 & 305 & 397 & 395 \\
NDF & 505 & 503 & 695 & 706 \\
CP & 166 & 166 & 102 & 105 \\
Particle size (mm) & 293 & 68 & 180 & 53 \\
\hline
\end{tabular}

BBL, unchopped big-bale grass silage; BBS, chopped big-bale grass silage; $\mathrm{HL}$, unchopped hay; HS, chopped hay; ADF, acid-detergent fibre; NDF, neutral-detergent fibre; $\mathrm{CP}$, crude protein $(\mathrm{N} \times 6 \cdot 25)$.

${ }^{*}$ For details of preparation of diets, see p. 110.

†Feeds were supplemented with $60 \mathrm{~g}$ mineral and vitamin supplement (Equivite, ) (per kg): Ca $100 \mathrm{~g}, \mathrm{P} 40 \mathrm{~g}, \mathrm{Na} 20 \mathrm{~g}$, Mg $20 \mathrm{~g}$, lysine $10 \mathrm{~g}$, Fe $300 \mathrm{mg}$, Zn $1000 \mathrm{mg}, \mathrm{Mn} 800 \mathrm{mg}$, Cu $800 \mathrm{mg}, \mathrm{mg}$, Se $10 \mathrm{mg}$, Co $10 \mathrm{mg}$, choline chloride $1000 \mathrm{mg}$, biotin $20 \mathrm{mg}$, pyridoxine $100 \mathrm{mg}$, thiamin $240 \mathrm{mg}$, cyanocobalamin $2000 \mu \mathrm{g}$, riboflavin $240 \mathrm{mg}$, pantothenic acid $480 \mathrm{mg}$, nicotinic acid $100 \mathrm{mg}$, folic acid $70 \mathrm{mg}$, $\alpha$-tocopherol $10 \mathrm{~g}$, cholecalciferol $0.05 \mathrm{mg}$, retinol $4.35 \mathrm{mg}$.

digestibilites of DM, ADF or CP were noted between the normal or chopped form of either forage. However, significantly $(P<0 \cdot 01)$ higher digestibilites of DM, ADF, NDF and $\mathrm{CP}$ were recorded for both the silages compared with both hays, reflecting the higher nutritive value of the silage compared with the hay.

\section{Digesta passage rate studies}

Recovery of marker in the faeces was $>95 \%$ for all feeds, and although differences existed between marker concentration on each forage ranging from 12.922 for $\mathrm{HS}$ to $29.178 \mathrm{mg} / \mathrm{g}$ for $\mathrm{BBS}$, the concentration of $\mathrm{Yb}$ in the faeces was easily detectable.

\section{Description of faecal excretion data using mathematical models}

The multi-compartmental time-independent model of Dhanoa et al. (1985) failed to converge with some of the faecal excretion data collected; thus, a workable solution was not attained and so the model was subsequently rejected from further analysis. The other compartmental models tested were the G1 time-independent model of Pond et al. (1988) and the three time-dependent models G2, G3, G4 of Pond et al. (1988).

Table 3 shows the $R^{2}$ data obtained when the four models of Pond et al. (1988) were fitted to the faecal excretion data. All models fitted the data with reasonable accuracy, with values ranging from 0.862 for HS G2 to 0.955 for HL G4. When tested on the HS and BBL diets the G2 model was significantly $(P<0.05)$ less accurate than the G3 (0.950) and G4 (0.955) models when fitted to HL data. BBS G2 was also significantly less $(P<0.05)$ accurate than the HL G4 model. For any given model there were no significant differences across or within diets. Overall, the G1 and G2 models described the data significantly less well than the G3 and G4 models. Although there was no significant difference between the G3 and G4 models, the G3 model was marginally more 
Table 2. DM intakes $(\mathrm{kg} / \mathrm{d})$ and in vivo apparent digestibility coefficients for the four experimental feeds offered to the four ponies at $15 \mathrm{~g} / \mathrm{kg}$ live weight $\dagger$

(Mean values)

\begin{tabular}{|c|c|c|c|c|c|c|}
\hline & \multicolumn{4}{|c|}{ Diet } & \multirow[b]{2}{*}{ SED } & \multirow[b]{2}{*}{ Statistical significance of effect } \\
\hline & BBL & BBS & $\mathrm{HL}$ & HS & & \\
\hline LW (kg) & $292^{\mathrm{b}}$ & $294^{\mathrm{b}}$ & $280^{\mathrm{a}}$ & $282^{\mathrm{a}}$ & $2 \cdot 51$ & * \\
\hline DM intake $(\mathrm{kg} / \mathrm{d})$ & $4 \cdot 27^{\mathrm{ab}}$ & $4.46^{\mathrm{b}}$ & $3.83^{a}$ & $3.88^{a}$ & 0.247 & * \\
\hline DM intake $e^{0.75}$ & 60.5 & $62 \cdot 3$ & $55 \cdot 9$ & $56 \cdot 3$ & $3 \cdot 380$ & NS \\
\hline \multicolumn{7}{|l|}{ Digestibility } \\
\hline DM & $0.67^{\mathrm{a}}$ & $0.67^{a}$ & $0.48^{\mathrm{b}}$ & $0.50^{\mathrm{b}}$ & 0.015 & $\star \star *$ \\
\hline ADF & $0.64^{\mathrm{a}}$ & $0.63^{\mathrm{a}}$ & $0.39^{b}$ & $0.42^{\mathrm{b}}$ & 0.019 & ** \\
\hline NDF & $0.62^{\mathrm{a}}$ & $0.61^{\mathrm{a}}$ & $0.43^{\mathrm{b}}$ & $0.46^{\mathrm{b}}$ & 0.014 & ** \\
\hline $\mathrm{CP}$ & $0.74^{\mathrm{a}}$ & $0.74^{\mathrm{a}}$ & $0.58^{\mathrm{b}}$ & $0.58^{\mathrm{b}}$ & 0.021 & ** \\
\hline
\end{tabular}

BBL, unchopped big-bale grass silage; BBS, chopped big-bale grass silage; HL, unchopped hay; HS, chopped hay; LW, live weight; ADF, acid-detergent fibre; NDF, neutral-detergent fibre; $\mathrm{CP}$, crude protein $(\mathrm{N} \times 6.25)$ ${ }^{\star} P<0.05,{ }^{\star \star} P<0.01$.

a,b Mean values within a row with unlike superscript letters were significantly different; ${ }^{\star}(P<0.05),{ }^{* *}(P<0.01)$.

†For details of diets and procedures, see Table 1 and p. 110

accurate than the G4 and was subsequently used for further compartmental analysis.

Fig. 1 depicts the faecal excretion data from each pony and the average G3 (Pond et al. 1988) -fitted curves for all four forage diets. The pattern of marker excretion was similar for each diet, although in all cases the fitted curve failed to describe the early phase of marker excretion.

\section{Mean retention time of digesta within the total tract} determined using ytterbium-marked food

The average MRT for the four forages are detailed in Table 4. The average MRT across all models for BBL was significantly $(P<0.05)$ longer at $29 \mathrm{~h}$ compared with the other three forages, which ranged from $26 \mathrm{~h}$ for HL and $\mathrm{HS}$ to $27 \mathrm{~h}$ for BBS. The average values for the models indicated that the G2 model produced a significantly $(P<0.05)$ longer MRT value of $29 \mathrm{~h}$ than the G3, G4 and Thielmans et al. (1978) equation of $26.0 \mathrm{~h}$. The time-independent G1 model did not differ significantly from any of the other models when predicting MRT.

When considering the individual differences between the five models and the four forages, the G4 model for HL produced the shortest MRT of $23.8 \mathrm{~h}$, which differed significantly $(P<0.05)$ from all but the BBS value of $27.7 \mathrm{~h}$ for the values predicted by the G2 model, and all but the Thielmans et al. (1978) model when applied to the BBL diet.

The algebraic model of Thielmans et al. (1978) uses actual concentration of marker recovered in the faeces, and was therefore used as the standard method for comparing the accuracy of the MRT values obtained from the compartmental models

\section{Compartmental analysis}

The G3 model of Pond et al. (1988) best described the faecal excretion patterns obtained when $\mathrm{Yb}$ marker was offered as an oral pulse dose to the four ponies.

Table 3. Accuracy of fit, as determined by $R^{2}$, of the four mathematical models of Pond et al. (1988), for describing faecal excretion data using ytterbium-marked food in four ponies consuming four experimental feeds $\dagger$

(Mean values)

\begin{tabular}{|c|c|c|c|c|c|}
\hline \multirow[b]{2}{*}{ Model $\ddagger$} & \multicolumn{4}{|c|}{ Diet } & \multirow[b]{2}{*}{ Mean of models } \\
\hline & BBL & BBS & $\mathrm{HL}$ & $\mathrm{HS}$ & \\
\hline G1 & $0.855^{\mathrm{abc}}$ & $0.888^{a b c}$ & $0.910^{\mathrm{abc}}$ & $0.880^{\mathrm{abc}}$ & $0.883^{x}$ \\
\hline G2 & $0.865^{a}$ & $0.872^{\mathrm{ab}}$ & $0.875^{a b c}$ & $0.862^{\mathrm{a}}$ & $0.868^{x}$ \\
\hline G3 & $0.935^{a b c}$ & $0.905^{\mathrm{abc}}$ & $0.950^{\mathrm{bc}}$ & $0.923^{a b c}$ & $0.928^{y}$ \\
\hline G4 & $0.937^{\mathrm{abc}}$ & $0.902^{a b c}$ & $0.955^{\mathrm{c}}$ & $0.917^{\mathrm{abc}}$ & $0.927^{y}$ \\
\hline SED & \multicolumn{4}{|c|}{$0.0413 \S$} & \\
\hline Mean of diets & $0.898^{p}$ & $0.891^{\mathrm{p}}$ & $0.922^{w}$ & $0.895^{p}$ & \\
\hline SED & \multirow{2}{*}{\multicolumn{4}{|c|}{$0.0206 \|$}} & $0.0206 \rrbracket$ \\
\hline Statistical significance of effect & & & * & & * \\
\hline
\end{tabular}

BBL, unchopped big-bale grass silage; BBS, chopped big-bale grass silage; HL, unchopped hay; HS, chopped hay. ${ }^{*} P<0.05$.

a,b,c Mean values in a column or row (model and diet) with unlike superscript letters were significantly different $(P<0.05)$.

${ }^{x, y}$ Mean values in a column (model) with unlike superscript letters were significantly different $(P<0.05)$.

$\mathrm{p}, \mathrm{w}$ Mean values in a row (diet) with unlike superscript letters were significantly different.

† For details of diets and procedures, see Table and p. 110.

$\ddagger$ G1 to G4 time-dependent models of Pond et al. (1988).

$\S$ Model and diet SED.

II Diet SED.

q Model SED. 
(a)

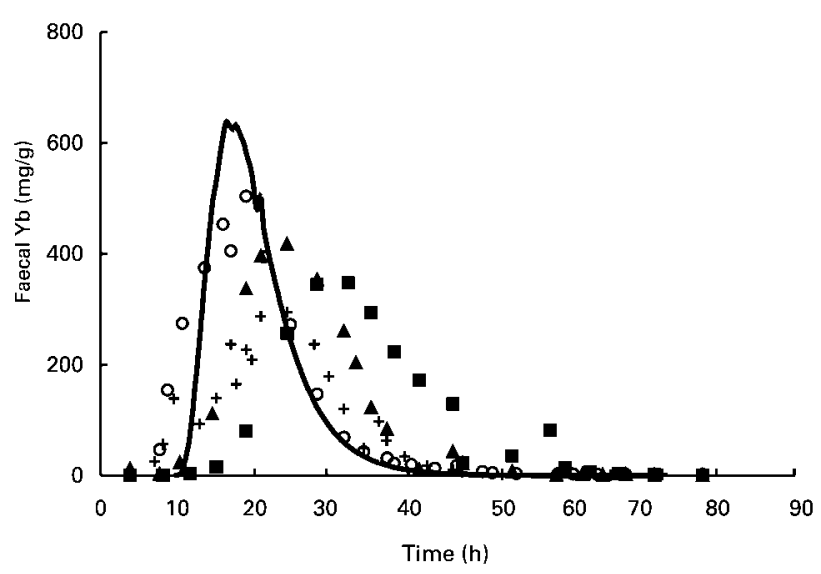

(c)

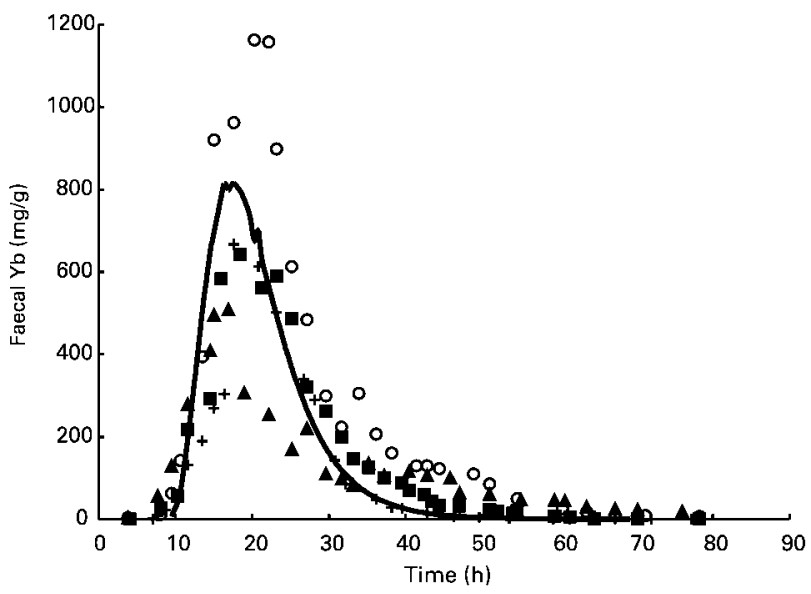

(b)

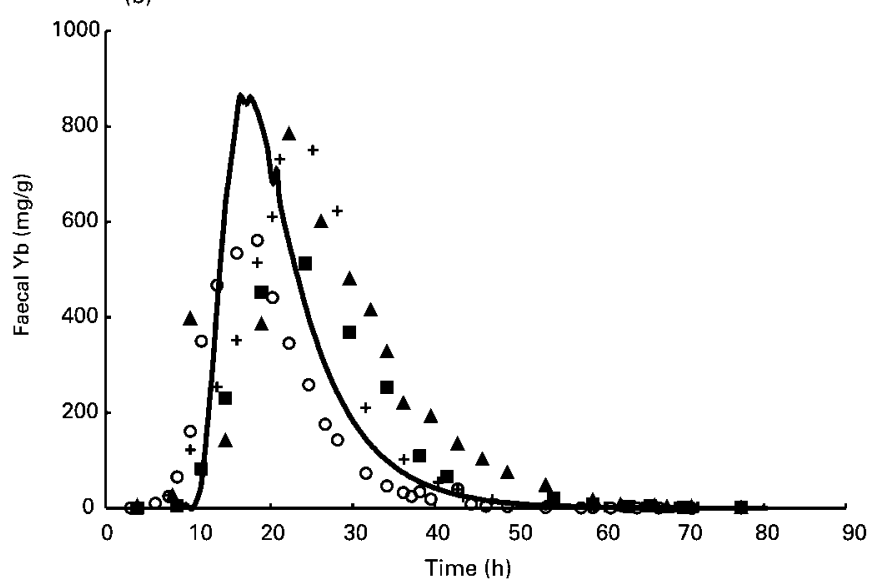

(d)

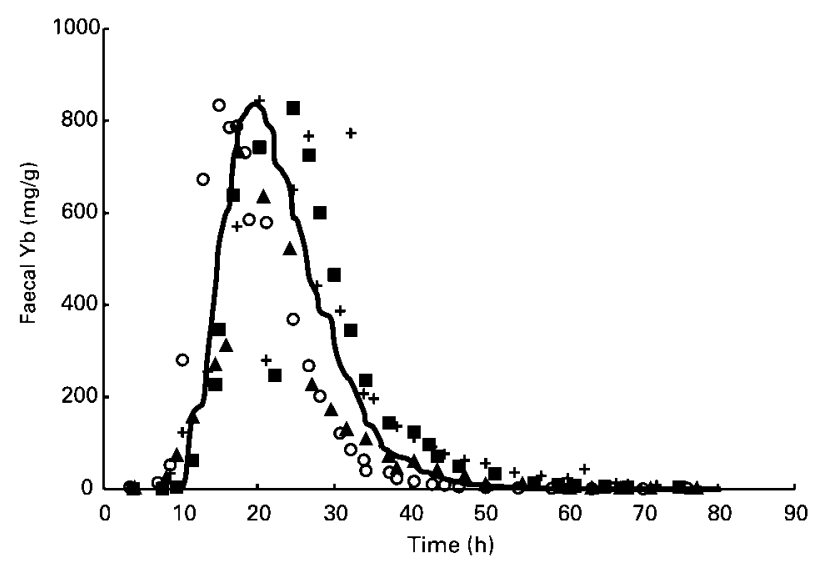

Fig. 1. Faecal excretion curves obtained using ytterbium-marked feed from ponies consuming unchopped big-bale grass silage (BBL, (a)), chopped big-bale grass silage (BBS, (b)), unchopped hay (HL, (c)) and chopped hay (HS, (d)) in four ponies. For details of diets and procedures, see Table 1 and p. 110. Individual points represent results from individual ponies. -, Average fitted curves using the G3 model of Pond et al. (1988). $R^{2}$ values: BBL 0.94, BBS 0.90, HL 0.95, HS, 0.93.

Table 5 details the mean passage rate and retention time parameters obtained when using the G3 time-dependent compartmental model. The BBL and HS appear to remain slightly longer in the $\lambda$ compartment, whereas the BBS and HL remain longer in the $\mathrm{k}_{2}$ compartment. The TD for both chop lengths of silage was slightly longer than was noted for the hay feed, but these differences were not significant. The significant $(P<0.05)$ difference in MRT between BBL and HL shows the BBL to be retained for $4.2 \mathrm{~h}$ longer than the HL diet.

\section{Discussion}

\section{Food composition}

The DM contents of the forages offered to the ponies in this experiment were similar to those recorded by the Ministry of Agriculture Fisheries and Food (1992) for samples of typical UK hay and big-bale grass silage.

While the $\mathrm{CP}(\mathrm{N} \times 6.25)$ contents for both forages are also similar to those quoted by the Ministry of Agriculture Fisheries and Food (1992), they are markedly higher than the values recorded in a previous experiment by MooreColyer (2000) of 44 (hay) and 111 (big-bale grass silage) $\mathrm{g} / \mathrm{kg}$ DM. ADF and NDF contents were within the range recorded by the Ministry of Agriculture Fisheries and Food (1992) for these forages.

\section{In vivo apparent digestibility}

The apparent digestibilities of DM, ADF, NDF and CP $(\mathrm{N} \times 6.25)$ for both $\mathrm{HS}$ and HL were significantly lower than for BBS and BBL and reflect the stage of growth of the grass at harvest, and thus the higher nutritive value of the silage compared with the hay. The apparent digestibility values for the silage agree with those of Keating (1998) and Moore-Colyer (2000), although the hay in this experiment was $10-30 \%$ more digestible than recorded in previous studies. These comparisons clearly demonstrate the variability of UK hay, and thus indicate that analysis of hay prior to ration formulation is advisable.

The $\mathrm{CP}(\mathrm{N} \times 6 \cdot 25)$ content of $103 \mathrm{~g} / \mathrm{kg} \mathrm{DM}$ and DM intake of $3.8 \mathrm{~kg}$ hay diet $/ \mathrm{d}$ in the present experiment meant that the 
Table 4. Retention times of digesta $(\mathrm{h})$, calculated from four mathematical models and one algebraic equation fitted to faecal excretion data obtained from four ponies given an oral pulse dose of ytterbium-marked food while consuming four experimental diets $†$

(Mean values)

\begin{tabular}{|c|c|c|c|c|c|}
\hline \multirow[b]{2}{*}{ Model‡ } & \multicolumn{4}{|c|}{ Diet } & \multirow[b]{2}{*}{ Mean of models } \\
\hline & BBL & BBS & $\mathrm{HL}$ & HS & \\
\hline G1 & $30 \cdot 6^{\text {de }}$ & $27 \cdot 5^{\text {abcde }}$ & $25 \cdot 1^{a b c}$ & $25 \cdot 6^{\mathrm{abc}}$ & $27 \cdot 2^{x y}$ \\
\hline G2 & $31 \cdot 0^{\mathrm{e}}$ & $27 \cdot 7^{\text {bcde }}$ & $28 \cdot 4^{\text {cde }}$ & $28 \cdot 1^{\text {cde }}$ & $28 \cdot 8^{y}$ \\
\hline G3 & $28 \cdot 2^{\text {cde }}$ & $27 \cdot 0^{\text {abcd }}$ & $24 \cdot 0^{\mathrm{ab}}$ & $24 \cdot 6^{\mathrm{abc}}$ & $25 \cdot 9^{x}$ \\
\hline G4 & $27 \cdot 9^{\mathrm{abcd}}$ & $26 \cdot 4^{\mathrm{abc}}$ & $23 \cdot 8^{\mathrm{ab}}$ & $25 \cdot 0^{\mathrm{abc}}$ & $25 \cdot 8^{x}$ \\
\hline Thielmans' equation§ & $27 \cdot 2^{\text {abcdef }}$ & $25 \cdot 3^{\text {abcd }}$ & $26 \cdot 1^{\text {abcd }}$ & $24 \cdot 9^{\text {abcd }}$ & $25 \cdot 9^{x}$ \\
\hline Mean of diets & \multicolumn{5}{|c|}{$1.920 \|$} \\
\hline SED & \multirow{2}{*}{\multicolumn{4}{|c|}{0.8599}} & $0.960 \dagger \dagger$ \\
\hline Statistical significance of effect & & & & & \\
\hline
\end{tabular}

BBL, unchopped big-bale grass silage; BBS, chopped big-bale grass silage; HL, unchopped hay; HS, chopped hay.

* $P<0.05$.

$\mathrm{a}, \mathrm{b}, \mathrm{c}, \mathrm{d}, \mathrm{e}, \mathrm{f}$ Mean values in a column or row (model or diet) with unlike superscript letters were significantly different $(P<0.05)$.

${ }^{x, y}$ Mean values in a column (model) with unlike superscript letters were significantly different $(P<0.05)$

${ }^{p, w}$ Mean values in a row (diet) with unlike superscript letters were significantly different $(P<0.05)$.

†For details of diets and procedures, see Table 1 and p. 110.

$\ddagger$ G1 to G4 time-dependent models of Pond et al. (1988).

$\S$ Thielmans et al. (1978).

|| Model and diet SED.

१ Diet SED.

†† Model SED.

Table 5. Rate parameters $\lambda$ and $k_{2}$ and calculated mean retention time (MRT) for the $\lambda$ compartment (LC), $\mathrm{k}_{2}$ compartment ( $\mathrm{kC}$ ), time delay (TD) and total tract MRT obtained from the Pond et al. (1988) G3 model applied to faecal excretion data collected from ponies given an oral dose of ytterbiummarked food while consuming four experimental feeds $\dagger$

\begin{tabular}{lcccccc}
\hline \multicolumn{5}{c}{ Diet } & & \\
\cline { 2 - 4 } & BBL & BBS & HL & HS & SED & Statistical significance of effect \\
\hline$\lambda$ & 0.67 & 0.81 & 0.61 & 0.34 & 0.381 & NS \\
LC & 10.64 & 7.03 & 6.65 & 10.61 & 2.376 & NS \\
K $_{2}$ & 0.186 & 0.151 & 0.176 & 0.223 & 0.0556 & NS \\
KC & 6.55 & 8.73 & 7.58 & 4.85 & 2.751 & NS \\
TD & 11.05 & 11.26 & 9.79 & 9.05 & 1.068 & $*$ \\
MRT & $28.24^{\mathrm{b}}$ & $27.02^{\mathrm{a}}$ & $24.02^{\mathrm{a}}$ & $24.51^{\mathrm{a}}$ & $1.769^{\mathrm{a}}$ & \\
\hline
\end{tabular}

BBL, unchopped big-bale grass silage; BBS, chopped big-bale grass silage; HL, unchopped hay; HS, chopped hay. ${ }^{\mathrm{a}, \mathrm{b}}$ Mean values within a row with unlike superscript letters were significantly different $(P<0.05)$ ${ }^{*} P<0.05$.

†For details of diets and procedures, see Table 1 and p. 110.

ponies exceeded their theoretical daily digestible $\mathrm{CP}$ requirement of $176 \mathrm{~g} / \mathrm{d}$ (National Research Council, 1989). This is in contrast to an earlier study of Moore-Colyer \& Longland (2000), where, despite a good DM intake of $4.95 \mathrm{~kg} / \mathrm{d}$, the low CP content of only $44 \mathrm{~g} / \mathrm{kg}$ DM, coupled with the low CP digestibility coefficient of $0 \cdot 2$ meant that the ponies' intakes were below the National Research Council (1989) recommendations for daily CP intake. However, despite the positive relationship between $\mathrm{CP}$ content and digestibility noted in the present study, a total collection apparent digestibility experiment cannot determine the site where the $\mathrm{CP}$ is digested. Thus, the availability of $\mathrm{CP}$ in forage diets may be low, as fibrous feedstuffs are largely degraded by microbial action in the large intestine. Therefore, studies that examine $\mathrm{CP}$ digestibility within the different segments of the equid gastrointestinal tract are required if the bioavailability of $\mathrm{CP}$ in forages is to be determined.

In agreement with Cymbaluk (1990) and Cuddeford et al. (1995), the present experiment indicated that a negative correlation exists between DM digestibility and the
ADF and NDF contents of forages. This relationship requires further study, as it could prove a useful tool in predicting the apparent digestibility of forage from laboratory analysis alone.

\section{Digesta passage rate studies}

Mathematical modelling of faecal excretion data. Successful mathematical modelling of faecal excretion data has the potential to yield useful information to horse-owners on the flow of digesta through the individual gut compartments, as well as giving a value for MRT for both the individual compartments and for the total tract. However, in order to make full use of this process, selection of an appropriate model that accurately describes the pattern of faecal excretion must be done.

The method employed in the present experiment for assessing the 'goodness of fit' of the models tested was by examining the $R^{2}$ values. On this basis, it was found that the time-dependent compartmental models of Pond 
et al. (1988) fitted the faecal excretion data much better than the time-independent models. Moreover, the fact that the model of Dhanoa et al. (1985) did not fit all the data collected further indicated that the digesta flow in the ponies was a time-dependent process. Mertens (1989) suggested that when equal outflow rates exist for the ascending $(\lambda)$ and descending $\left(\mathrm{k}_{2}\right)$ phases of faecal excretion curves it is an indication that digesta passage is in fact a time-dependent process. The pattern of marker excretion in the present experiment showed similar rates for the ascending and descending phases of the curves, a trend also noted in an preliminary study in ponies fed hay cubes and a oat hull-naked oat $(66: 33$, w/w) diet by Moore-Colyer (2000). Thus, all the evidence to date would seem to suggest that digesta flow in ponies fed fibrous diets is a time-dependent process and is therefore best described using time-dependent models.

Although the models of Pond et al. (1988) were originally developed for ruminant animals, their form allows them to describe accurately the passage of marked particles through a tubular gut, because the initial rate function (i.e. the rate of appearance of marker in the faeces) is zero and increases with time (Pond et al. 1988). This is a key factor of time-dependent models that allows them to deal with the pattern of digesta passage through the gastrointestinal tract of the horse.

Moore et al. (1992) found the best fits for ram faecal excretion data were achieved using the higher order of $\gamma$-functions, i.e. the G3 and G4 models, with poorer fits obtained from the G1 and G2 models. This was also noted by Moore-Colyer (2000) and in the present experiment, as the best-fit model proved to be the higher $\gamma$ order of G3.

Pond et al. (1988) suggested that the use of time-dependent models produced better agreement between actual and fitted data in the early stages of marker excretion. However, as can be seen in Fig. 1, the models did not fit the early phase of marker excretion in all four diets examined in the present experiment and tended to overestimate the time before actual appearance of marker in the faeces. Moore-Colyer (2000) also noted this when feeding an oat hull-naked oats mixture to ponies. Failure to collect sufficient numbers of samples during the early stages of marker excretion is frequently blamed for poor agreement between predicted and observed results (Dhanoa et al. 1985; Matis et al. 1989). However, in the current experiment, faecal collections started $8 \mathrm{~h}$ post-dosing, which resulted in about seven data points compiling the ascending phase of the graphs. Moreover, the best fit was achieved using the G3 model, which generally requires good quality data in order to model a faecal excretion curve (Pond et al. 1988); thus, lack of data in the early phases of marker excretion was clearly not the problem here. The lack of accuracy in describing the early expulsion of marker is more likely to be explained by the fact that the Pond et al. (1989) model was produced to describe digesta passage through a ruminant animal gut and that the considerably shorter MRT noted in equids, and thus the faster appearance of marker in the faeces compared with ruminant animals, cannot be adequately described using a ruminant animal model.
Total tract mean retention time. MRT can be derived algebraically using the Thielmans et al. (1978) equation, which because it uses the collected faecal marker data rather than assuming a continuous rate of faecal output, is regarded as the most accurate method of achieving total tract residence time (Warner, 1981). Uden et al. (1982), Pearson \& Merritt (1991) and Moore-Colyer (2000) have all used variations of this equation to establish MRT of hay in equids. These workers have reported MRT ranging from 23 to $29 \mathrm{~h}$, which are similar to the average values obtained for all the models in this experiment of 25 to $29 \mathrm{~h}$, but are slightly less than the 42 and $32 \mathrm{~h}$ recorded by Moore-Colyer (2000), when ponies were offered oat hulls-naked oats and hay cube diets. The average MRT of the HL and HS (26h) were significantly shorter than the $29 \mathrm{~h}$ recorded for the BBL diet. Pearson \& Merritt (1991) also reported a longer (5 h) MRT when ponies were fed a poorly degradable straw diet than when they consumed a more degradable hay diet. In the present experiment the hay diets were $18 \%$ less degradable than the silage diets and may have contributed to the shorter MRT. However, the BBS diet also had a significantly shorter MRT of $27 \mathrm{~h}$ than the BBL, but was equally well degraded. This anomaly is curious, because the shorter MRT of the BBS cannot be attributed to a shorter particle size as the HS has a retention time equal to that of the HL; thus, some other and as yet unexplained factor must have contributed to the shorter MRT.

Good agreement was seen for the MRT of all four forages between the Thielmans et al. (1978) G3 and G4 models, whereas the G2 model consistently over-estimated MRT. Although no significant difference existed between the G1 model and any of the other values, it did produce a $1.3 \mathrm{~h}$ longer retention time than the G3, G4 and Thielmans et al. (1978) models and may reflect the fact that the G1 model is a time-independent model. Lalles et al. (1991) and Gomez et al. (1992) also reported good agreement between both algebraic and compartmental models in early weaned dairy calves and sheep fed hay or concentrate diets, and this appears to be the case here, indicating that both the models of Pond et al. (1988) and Thielmans et al. (1978) can be used to determine MRT in equids.

However, no specific model is as yet recommended for estimating compartmental MRT in ruminant animals, and as the work done to date with equids is extremely limited, the choice of the G3 model for compartmental analysis was based on the $R^{2}$ data obtained in this experiment and on previous work by Moore-Colyer (2000).

Compartmental analysis. The general assumption when dealing with compartmental models is that the model consists of compartments where particle mixing may occur, e.g. rumen and abomasum, while the TD, where mixing is minimal, represents a minimum fixed time that is required for particles to pass through the gut and appear in the faeces (Matis et al. 1989). Most ruminant-animal researchers believe that the slower timeindependent $\left(k_{1}\right)$ compartment is the rumen, the faster time-dependent $\lambda$ compartment is a combination of the caecum and proximal colon, while the TD represents the passage of digesta through the omasum and the intestines, and is closely correlated with the first appearance of 
marker in the faeces (Grovum \& Williams, 1973; Pond et al. 1988). Theoretical consideration of the anatomy of the equid gastrointestinal tract suggests that the size, positioning and movement of the caecum would result in a short digesta retention time (i.e. the fast compartment), while its sac-like anatomy suggests that instantaneous mixing may occur and that outflow could be independent of residence time, i.e. a time-independent compartment. In contrast, the anatomy of the large colon, with its four sacculated sections divided by narrow flexures (Frandson, 1981), would pre-dispose this part of the gut to be the time-dependent section. Although it is possible that particle mixing within each of the distinct regions of the colon occurs rapidly, implying time-independency, the passage through the complete organ would be time-dependent. The rate constant for the time-dependent section of the faecal excretion curve, $\lambda$, is a sum of two or more timeindependent rates, thus passage of digesta through the large colon could easily fit such a mathematical equation. Argenzio et al. (1974) found the passage of digesta was particularly slow from the ventral to the dorsal colon (through the pelvic flexure) and from the dorsal to the small colon. In addition, fluid marker was retained for prolonged periods in the large colon, having passed from the stomach through the caecum into the proximal colon relatively quickly; thus, passage through the large intestine could be a time-dependent process.

However, such clear apportioning of the different equid gut compartments according to the rate at which digesta passes through the tract cannot be conclusively achieved from the data collected in the present experiment. The values presented in Table 5 show the BBL and HS diets to have longer retention times for the time-dependent $\lambda$ compartment, while BBS and HL had longer retention times for the time-independent $\mathrm{k}$ compartment. Thus, unlike the conclusions of the ruminant-animal researchers Matis (1972) and Ellis et al. (1994), time-dependency cannot be consistently associated with the faster turnover compartment.

Faichney \& Boston (1983) found that in ruminant animals under certain dietary circumstances outflow from the caecum could be slower than from the rumen. This suggests that the dietary ingredients, or the manner in which the food is presented to the animal, can influence the rate at which digesta passes through the different chambers of the gut. However, the results of the present experiment show no clear influence of forage type or particle size on the passage rate of digesta through the different gut compartments, therefore, no informed conclusion as to caecal or colonic digesta passage rates can be formed.

The TD is thought to represent the narrow tubular sections of the gut, where food has little opportunity to mix, thus a time-delay factor is introduced to account for this (Ellis et al. 1994; Matis et al. 1989). Moore-Colyer (2000) found that a TD compartment was clearly identified when Cr-marked food was placed into the caecum of the ponies and thus passed through the hindgut only, and that the value for the TD was similar for large intestine passage rate and total tract passage rate, indicating that it may relate to the small colon, where faeces collects before excretion. This suggests that the time digesta remains within the stomach and small intestine are included in the $\lambda$ and $\mathrm{k}_{2}$ compartment retention times and not in the TD. While no clear differences exist between the two compartments between the hay and silage diets offered here, there is a tendency for the TD to be $2 \mathrm{~h}$ shorter for the hay than for the silage. This may have been the major contributing factor to the difference in total tract MRT between the hay and BBL diets.

The lack of a definite conclusion on compartmentalising the gut is not a problem unique to the present experiment. Having developed a multi-compartment model, which accurately described eighty sets of ruminant animal faecal excretion data, Dhanoa et al. (1985) could not say with certainty which of the two main rate constants represented the rumen and which represented the caecum. Results from their first study indicated that $\mathrm{k}_{1}$ was the rumen, while $\mathrm{k}_{2}$ was the caecum. However, their second study did not produce similar conclusions. It seems that clear biological interpretation of modelled faecal excretion data is extremely difficult. In the present study, the lack of clear compartment identification could be a result of the use of ruminant animal models for fitting pony faecal excretion data. However, as the $R^{2}$ values indicate, the models did accurately describe the marked faecal excretion patterns of the ponies. Alternatively, the modelling process itself, which relies on end-point excretion data, could lack sufficient sensitivity to allow the prediction of digesta flow through the different compartments of the gut. Furthermore, if faecal excretion data can be successfully modelled using a wide variety of models (time-independent G1 and time-dependent two compartment models G2, G3 and G4) that make different assumptions regarding digesta flow, the ability of the modelling procedure to partition flow through the various segments of the equid digestive tract may be limited.

Considerably more work is required in this area before definitive conclusions can be drawn regarding digesta passage rate through the different compartments of the equid gastrointestinal tract. The limitations illustrated here may be overcome if a model were derived specifically for equids based on the rate of passage of digesta through a horse's gut rather than using ruminant animal models that are based on much slower rates of passage. Moreover, rate of passage data is known to be very variable, so the limitations in the quantity of data produced from this $4 \times 4$ Latin square experiment means that the conclusions that can be drawn on gut compartmentalisation are minimal. More animals could be used, although power calculations based on current variability levels suggest that four times the number of ponies would be required if significant differences were to be detected.

\section{Conclusions}

Results from the present experiment indicate that big-bale grass silage in both long and chopped form is readily accepted and digested by ponies and can be used as a replacement for hay in diets for horses. Moreover, the higher nutrient content and digestibility of silage makes it an ideal forage for performance horses as the nutrient content of silage is significantly greater than hay on a per $\mathrm{kg}$ basis. 
$\mathrm{Yb}$ is a successful external marker for determining total tract MRT of fibre-based diets in ponies. Chop length of forages appears not to influence digesta MRT and, in addition, marker excretion patterns allowed existing time-dependent compartmental mathematical models to be successfully applied to faecal excretion data. Total tract MRT was successfully calculated from model rate parameters, and although compartmental retention times could be obtained, the variability of the data hampered the production of a conclusive biological interpretation on the compartmentalisation of the different segments of the equid gastrointestinal tract.

\section{References}

Argenzio RA, Southworth M \& Stevens CE (1974) Sites of organic acid production and absorption in the equine gastrointestinal tract. Am J Physiol 226, 1043-1050.

Association of Official Analytical Chemists (1990) Official methods of Analysis, 15th ed. Arlington, VA: AOAC.

Cochran RC \& Gaylean ML (1994) Measurement of in vivo forage digestion by ruminants. In Forage Quality, Evaluation and Utilisation, chapter 15, pp. 613-639 [GC Fahey, M Collins, DR Mertens and LE Moser, editors]. Madison, WI: American Society of Agronomy Inc.

Corino C, Fontana F, Miraglia N \& Zanetti P (1992) Validation of a two interacting compartmental (TIC) model for estimating digesta passage in horses. Europaische Konferenz uber die Ernahrung des Pferdes, 39-41.

Cuddeford DC, Pearson RA, Archibald RF \& Muirhead RH (1995) Digestibility and gastrointestinal transit time of diets containing different proportions of alfalfa and oat straw given to Thoroughbreds, Shetland ponies, Highland ponies and donkeys. Anim Sci 61, 407-417.

Cymbaluk NF (1990) Comparison of forage digestion by cattle and horses. Can J Anim Sci 70, 601-610.

Dhanoa MS, Siddons R, France J \& Gale DL (1985) A multicompartmental model to describe marker excretion patterns in ruminant faeces. Br J Nutr 53, 663-671.

Ellis WC, Matis JH, Hill TM \& Murphy MR (1994) Methodology for estimating digestion and passage kinetics of forages. In Forage Quality, Evaluation and Utilisation, chapter 7, pp. 682-756 [GC Fahey, M Collins, DR Mertens and LE Moser, editors]. Madison, WI, USA: American Society of Agronomy.

Ellis WC, Matis JH \& Lascano C (1979) Quantitating ruminal turnover. Fed Proc 38, 2702-2706.

Faichney GJ \& Boston RC (1983) Interpretation of the faecal excretion patterns of solute and particle markers introduced into the rumen of sheep. J Agric Sci Camb 101, 575-581.

Frandson RD (1981) Anatomy and Physiology of Farm Animals, chapter 19. Philadelphia, PA, USA: Lea and Febiger.

Gomez L, Lalles JP, Bogaërt C \& Poncet C (1992) Kinetics of particulate and solute marker passage in sheep supplemented with cationomycin and lasalocid antibiotics. Comparisons among methods for calculating mean retention time. Reprod Nutr Dev 32, 173-190.

Grovum WL \& Williams VJ (1973) Rate of passage of digesta in sheep. 4. Passage of marker through the alimentary tract and the biological relevance of rate-constants derived from the changes in concentration of marker in faeces. Br J Nutr $\mathbf{3 0}$, 313-329.

Jackson S (1998) The digestive tract of the horse - practical considerations. In Advances in Equine Nutrition, pp. 1-11 [J Pagan, editor]. Nottingham: Nottingham University Press.
Keating F (1998) A comparison of the intake and digestibility of four forages by ponies. Proceedings of the 2nd Warwickshire Horse Conference. Oxford, UK: Blackwell Scientific Publications.

Lalles JP, Delval E \& Poncet C (1991) Mean retention time of dietary residues within the gastrointestinal tract of the young ruminant: a comparison of non-compartmental (algebraic) and compartmental (modelling) estimation methods. Anim Food Sci Technol 35, 139-159.

Matis JH (1972) Gamma time-dependency in Blaxter's compartmental model. Biometrics, 28, 597-602.

Matis JH, Wehrly TE \& Ellis WC (1989) Some generalised stochastic compartment models for digesta flow. Biometrics 45, 703-720.

Mertens DR (1989) Evaluating alternative models of passage and digestion kinetics. In Modelling Digestion and Metabolism in Farm Animals, 3rd International Workshop [AB Robertson and DP Poppi, editors]. Canterbury, New Zealand: Lincoln University.

Milne JA, MacRae JC, Spence AM \& Wilson S (1978) A comparison of the intake and digestion of a range of forages at different times of the year by the sheep and red deer (Service elaphus). Br J Nutr 40, 347-357.

Ministry of Agriculture, Fisheries and Food (1992) UK Tables of Nutritive Value and Chemical Composition of Feedingstuffs. Aberdeen: Rowett Research Services Ltd.

Moore JA, Pond KR, Poore MH \& Goodwin TG (1992) Influence of model and marker on digesta kinetic estimates for sheep. J Anim Sci 70, 3528-3540.

Moore-Colyer MJS (2000) Studies on the degradation kinetics of botanically diverse fibrous feeds and their apparent digestbility and rate of passage when fed to ponies. $\mathrm{PhD}$ Thesis, University of Edinburgh.

Moore-Colyer MJS \& Longland ACL (2000) In vivo apparent digestibility of four types of conserved forage by ponies. Anim Sci 71, 527-534.

National Research Council (1989) Nutrient Requirements for Horses, 5th ed. Washington, DC: National Academy Press.

Nyberg MA, Potter GD \& Gibbs PG, et al. (1993) Flow Rate Through Equine Small Intestine Determined With Soluble and Insoluble Indicators Given in a Pulse and Steady State Dose, College Station, TX: Texas A \& M University.

Pearson RA \& Merritt JB (1991) Intake, digestion and gastrointestinal transit time in resting donkeys and ponies and exercised donkeys given ad libitum hay and straw diets. Equine Vet $\mathbf{J} \mathbf{2 3}$, 339-343.

Pond KR, Ellis WC, Matis JH, Ferreiro HM \& Sutton JD (1988) Compartment models for estimating attributes of digesta flow in cattle. Br J Nutr 60, 571-595.

Teeter RG, Owens FN \& Mader TL (1984) Ytterbium chloride as a marker for particulate matter in the rumen. J Anim Sci $\mathbf{5 8}$, 465-473.

Thielmans MF, Francois E, Bodart C \& Thewis A (1978) Mesure du transit gastrointestinal chez le porc a l'aide des radiolanthides. Comparison avec le mouton (Gastrointestinal transit in the pig: measurement using radioactive lanthanides. Comparison with sheep). Ann Biol Anim Biochim Biophys 18, 237-247.

Uden P, Rounsaville TR, Wiggans GR \& Van Soest PJ (1982) The measurement of liquid and solid digesta retention in ruminants, equines and rabbits given timothy (Phleum pratense) hay. Br J Nutr 48, 329-339.

Vander Noot GW \& Gilbreath EB (1970) Comparative digestibility of forages by geldings and steers. J Anim Sci 31, 351-355.

Warner ACI (1981) Rate of passage of digesta through the gut of mammals and birds. Nutr Abstr Rev 51B, 789-820. 